\title{
CONSUMO COLABORATIVO: PERSPECTIVAS, OLHARES E ABORDAGENS PARA UM CONCEITO EM CONSTRUÇÃO'
}

\author{
Collaborative consumption: prospects, observations, and \\ approaches for a concept in construction
}

Consumo colaborativo: perspectivas, observaciones y criterios para un concepto en construcción

\author{
Ana Cirne Paes de Barros \\ Instituto Federal de Educação, Ciência e Tecnologia, campus Natal, Rio Grande do Norte, Brasil. \\ Professora do Instituto Federal de Educação, Ciência e Tecnologia, campus Cidade Alta. Doutoranda em \\ Comunicação pelo Programa de Pós-Graduação em Comunicação da Universidade Federal de Pernambuco, \\ sob orientação da professora doutora Karla Patriota. \\ E-mail: anapaesdebarros@gmail.com
}

\section{Karla Regina Macena Pereira Patriota}

Universidade Federal de Pernambuco, Pernambuco, Brasil.

Pós-Doutorado pela University of Cambridge, doutora em Sociologia pela Universidade Federal de Pernambuco. Professora Adjunta 4 do curso de Publicidade e Propaganda e do Programa de Pós-Graduação em Comunicação da Universidade Federal de Pernambuco.

E-mail:k.patriota@gmail.com

RESUMO Apesar de evidente nas práticas contemporâneas de consumo e comunicação, o que se convencionou chamar de "consumo colaborativo" ainda agrupa uma série de questionamentos e reflexões em torno de sua semântica. Este artigo, ancorado na perspectiva bibliométrica, analisa os trabalhos disponíveis no Portal de Periódicos da Capes/MEC e na Biblioteca Digital Brasileira de Teses e Dissertações que contenham em sua proposta de pesquisa a expressão "consumo colaborativo" para investigar de que modo os pesquisadores brasileiros abordam o conceito e, em seguida, problematiza suas postulações.

PALAVRAS-CHAVE Consumo, Consumo colaborativo, Bibliometria.

ABSTRACT Despite being evident in consumption and communication practices in the contemporary time, the so-called "collaborative consumption" also includes a series of questions and reflections around its semantics. This article, anchored in bibliometric perspective, analyzes the papers available in the Capes/MEC Journal Database and the Brazilian Digital Library of Theses and Dissertations which contain in their research proposal the term "collaborative consumption" to investigate how the Brazilian researchers approach the concept and then discusses its postulations.

KEYWORDS Consumption, Collaborative consumption, Bibliometrics.

RESUMEN A pesar de evidente en las prácticas contemporáneas de consumo y comunicación, lo que se llama "consumo colaborativo" también incluye una serie de preguntas y reflexiones en torno a su semántica. Este artículo, anclado en una perspectiva bibliométrica, analiza los trabajos disponibles en el Portal Capes/MEC y en la Biblioteca Digital Brasileña de Tesis y Disertaciones que contienen en su propuesta de investigación el término "consumo colaborativo" para investigar cómo los investigadores brasileños se acercan al concepto y luego analiza sus postulados.

PALABRAS CLAVE Consumo, Consumo colaborativo, Bibliometría.

1. Trabalho apresentado no Grupo de Trabalho 1 - Comunicação e consumo: cultura empreendedora e espaço biográfico, do $6^{\circ}$ Encontro de GTs do Congresso Internacional em Comunicação e Consumo (Comunicon), realizado nos dias 14 e 15 de outubro de 2015 na cidade de São Paulo, SP. Após o evento, o artigo foi reformulado para esta publicação. 


\section{INTRODUÇÃO}

A expressão "consumo colaborativo" vem sendo difundida nos últimos tempos como uma prática mais racional, menos degradante e mais sustentável. Tal associação se deve ao fato dessa forma de consumir implicar, na maioria das vezes, na utilização coletiva de um bem ou serviço ou no repasse e reutilização de produtos de segunda mão, o que amplia o tempo de vida dos bens.

Entre outros aspectos relevantes que convêm destacar, o fenômeno do consumo colaborativo está ambientado dentro da lógica do capitalismo contemporâneo, em um modelo de sociedade que atua em rede, marcadamente influenciada e dependente de recursos de tecnologia de informação e comunicação. Esses aspectos, é importante dizer, contribuíram para que tais experiências de consumo pudessem ser significativamente modificadas e ampliadas ao longo dos tempos.

Portanto, a efervescência do fenômeno, arriscamos dizer, é resultante de um cenário social complexo e multifacetado. Por outro lado, não é novo, nem tão recente, conforme é possível observar em algumas experiências antigas, vide os empréstimos e as formas de acesso às bibliotecas públicas.

$\mathrm{Na}$ atualidade, temos visto diversos exemplos de pessoas compartilhando espaços de suas residências ou meios de transporte como veículos e bicicletas, ou tendo acesso a roupas, brinquedos e livros apenas pelo tempo que estes objetos lhes são úteis. Também é usual presenciar trocas de serviços entre indivíduos de acordo com a habilidade e competência de cada um.

No entanto, apesar da evidência empírica de uma alteração nos processos mais tradicionais do consumo de bens e serviços, sobre o conceito em si, ainda recaem diversas ambiguidades principalmente quando confrontadas com as práticas dos indivíduos e das organizações que dizem praticar o "consumo colaborativo".

A inexistência de uma definição mais precisa sobre o conceito dificulta a compreensão do próprio fenômeno em questão. Para além de uma abordagem especificamente semântica ou epistemológica, ter uma reflexão mais sólida e problematizada sobre os processos que vêm sendo praticados passa pelo estabelecimento de um conceito consolidado. Daí a necessidade de refletir sobre os termos tratados como sinônimos, sobre a forma pela qual a expressão é referenciada e, além disso, associá-la às práticas de consumo existentes.

Diante do exposto, esse trabalho se propõe a demonstrar o estado da arte do "consumo colaborativo". Inicialmente, trazemos a abordagem de autores como Felson e Speath (1978), Ray Algar (2007), Botsman e Rogers (2011) e Belk (2013) sobre a expressão. Em seguida, catalogamos e analisamos como vêm sendo produzidos os trabalhos acadêmicos envolvendo o tema no Brasil. A intenção é compreender como se dá o campo das produções acadêmicas sobre o "consumo colaborativo" no país. Existe uma uniformidade conceitual a respeito do tema? Quantas publicações existem? A que áreas do conhecimento humano estão vinculadas estas publicações? Quando foram produzidos os trabalhos?

Ancorado na perspectiva bibliométrica, este estudo analisa os trabalhos disponíveis no Portal de Periódicos da Capes/MEC e na Biblioteca Digital Brasileira de Teses e Dissertações (BDTD) que contenham em sua proposta de pesquisa a expressão "consumo colaborativo". Pretendemos, com esse levantamento da produção contemporânea, traçar as primeiras pistas para a articulação e sistematização de um conceito sobre "consumo colaborativo". 


\section{O CENÁRIO DO ESTUDO SOBRE "CONSUMO COLABORATIVO"2}

A expressão "consumo colaborativo" foi utilizada, desde 1978, por Felson e Speath (1978), para se referir a jantares entre amigos ou à utilização de eletrônicos domésticos por um grupo de pessoas. Os autores conceituaram a expressão como: "Aqueles eventos nos quais uma ou mais pessoas consomem bens ou serviços no processo de se engajar em atividades conjuntas com um ou mais indivíduos”3 (Ibidem, p. 614, tradução nossa).

Mais direcionados para os estudos de Administração e Marketing, Felson e Speath (1978) pareciam estar preocupados em alertar sobre a interdependência entre as pessoas e a consequente interlocução do comportamento do consumidor com diversos aspectos das suas redes de contato. Queriam, portanto, chamar atenção para o fato do consumo não estar vinculado apenas às inclinações pessoais.

Após essa referência, foi apenas em 2007 que Ray Algar, um analista de mercado, publicou artigo na revista Leisure Report sobre "consumo colaborativo". A questão levantada pelo profissional era: o que acontece quando os consumidores começam a compartilhar conhecimento? Para Algar (2007), o "consumo colaborativo" era uma "prática de partilha, empréstimos comerciais, aluguel e trocas”, própria do século XXI. O autor entendia que, a partir desse processo, consumidores colaboravam on-line para trocar produtos e serviços. A ênfase de suas explanações se concentrava no estabelecimento de preços e nos descontos que os consumidores conseguiam quando se uniam.

Em 2011, Botsman e Rogers lançaram o livro o que é meu é seu: como o consumo colaborativo vai mudar o nosso mundo. Desde sua publicação, a obra e seus autores passaram a ser conhecidos como referências quando se trata do fenômeno aqui estudado, conforme será possível constatar na pesquisa bibliométrica. Conceituam o termo como "um novo mecanismo econômico e social promissor que começa a equilibrar as necessidades individuais com as das nossas comunidades e as do planeta" (BOTSMAN; ROGERS, 2011, p. 53).

Mais recentemente, o professor da York University no Canadá e especialista em estudos sobre compartilhamento ${ }^{4}$ Belk (2013, p. 3, tradução nossa) definiu "consumo colaborativo como: "pessoas coordenando a aquisição e distribuição de um recurso por uma taxa ou outra compensação"s.

Para o autor, o consumo colaborativo não deve ser entendido como Felson e Speath (1978) e Botsman e Rogers (2011) abordaram. Em relação à primeira dupla, o professor critica a utilização de uma definição muito ampla e não focada na aquisição e distribuição de recursos. Já em relação à segunda, contesta a amplitude de práticas entendidas como exemplos do conceito: partilha, troca, empréstimo, comércio, aluguel, doação e

2. Usaremos aspas quando mencionarmos consumo colaborativo neste texto porque acreditamos e defendemos que o termo ainda não define o seu conceito.

3. No original: "Those events in which one or more persons consume economic goods or services in the process of engaging in joint activities with one or more others.”'

4. Todas as vezes que mencionarmos compartilhamento nas obras de Belk, estamos nos referindo à palavra em inglês sharing.

5. No original: "is people coordinating the acquisition and distribution of a resource for a fee or other compensation". 
compartilhamento. Seria, portanto, necessária a exclusão das atividades sem compensação, como as doações e o couchsurfing ${ }^{6}$, por exemplo.

A inexistência de consenso ou de abordagens teóricas mais consolidadas sobre o "consumo colaborativo", somada à constatação empírica de haver certa confusão em relação ao significado do fenômeno, reforça a importância da realização de uma pesquisa bibliométrica, como desenvolveremos a seguir.

\section{UMA INCURSÃO NOS TRABALHOS PUBLICADOS SOBRE "CONSUMO COLABORATIVO"}

No período de 19 de abril a 5 de maio de 2016, realizamos uma busca pelo assunto (consumo colaborativo) no Portal de Periódicos da Capes/ $\mathrm{MEC}^{7}$ e na BDTD. ${ }^{8}$ Esses dois ambientes virtuais foram escolhidos por serem as duas maiores bases de dados acadêmicos no Brasil. Mesmo cientes de que os dois repositórios não contemplam a totalidade dos trabalhos e pesquisas desenvolvidas, acreditamos ser possível analisar, por meio deles, boa parte dos estudos já realizados sobre o tema.

No Portal de Periódicos da Capes estavam listados 6 (seis) trabalhos relacionados ao tema. Na BDTD havia 3 (três), sendo que dois deles coincidiam com trabalhos já encontrados no Portal de Periódicos. Desse modo, coletamos para a análise 7 (sete) trabalhos resultantes da busca, os quais apontamos na Tabela 1:

Dentre os resultados encontrados, 3 (três) são artigos, 1 (um) é trabalho de conclusão de curso e 3 (três) são dissertações. Um dos artigos é o recorte de uma das dissertações também analisadas, isto é, são de autoria da mesma pessoa e contêm a mesma abordagem. A inexistência de teses a respeito do tema e a incipiente quantidade de trabalhos indicam que estamos nos primeiros passos das pesquisas que abarcam tal panorama de consumo. O que não significa, a priori, que os pesquisadores em questão não trouxeram contribuições inéditas e aprofundadas.

$\mathrm{Na}$ análise da produção em pauta podemos inferir que os autores estão mais preocupados em analisar iniciativas e casos específicos e, principalmente, em avaliar o crescimento do fenômeno no país. Parece ficar em segundo plano a problematização das suas práticas como um fenômeno nomeadamente de consumo e que, por isso, é multifacetado, dinâmico e de caráter social.

A área prioritária que origina os estudos sobre "consumo colaborativo" é a Administração e suas abordagens transdisciplinares (5 trabalhos): economia, contabilidade e gestão empresarial. Essas publicações reforçam uma abordagem de "como fazer", isto é, como atender a demanda do público ou do mercado.

6. Couchsurfing é uma rede social que agrupa interessados em oferecer e usufruir de acomodações gratuitas em diversos países do mundo. Os membros recebem e se hospedam sem nenhuma troca monetária.

7. O Portal de Periódicos da Capes/MEC oferece ao pesquisador acesso a 37 mil publicações nacionais e internacionais em todas as áreas de conhecimento. Disponível em: <https:// goo.gl/86CQQ>.

8. A Biblioteca Digital Brasileira de Teses e Dissertações (BDTD) reúne todas as teses e dissertações defendidas no Brasil e por brasileiros no exterior. Disponível em: <https:// goo.gl/qrE0p9>. 
Tabela 1. Relação de trabalhos sobre "consumo colaborativo" encontrados no Portal de Periódicos da Capes e no BDTD.

\begin{tabular}{|c|c|c|c|c|}
\hline & $\begin{array}{c}\text { Título e } \\
\text { Autor(a) do trabalho }\end{array}$ & Tipo & Ano & Área de concentração \\
\hline \multirow{3}{*}{1} & O consumo colaborativo de transporte & \multirow{3}{*}{ Dissertação } & \multirow{3}{*}{2012} & \multirow{3}{*}{$\begin{array}{l}\text { Economia, Administração } \\
\text { e Contabilidade }\end{array}$} \\
\hline & $\begin{array}{l}\text { individual car sharring e o processo decisório } \\
\text { do consumidor na cidade de São Paulo }\end{array}$ & & & \\
\hline & Autora: Regina da Silva Ornelas & & & \\
\hline \multirow[t]{2}{*}{2} & $\begin{array}{l}\text { Impactos do consumo colaborativo de } \\
\text { veículos elétricos na cidade de São Paulo }\end{array}$ & \multirow[t]{2}{*}{ Artigo } & \multirow[t]{2}{*}{2013} & \multirow[t]{2}{*}{ Administração } \\
\hline & Autora: Regina da Silva Ornellas & & & \\
\hline \multirow[t]{2}{*}{3} & $\begin{array}{l}\text { La lógica espacial del intercambio de } \\
\text { casas: una aproximación a las nuevas } \\
\text { geografías de lo cotidiano en el turismo } \\
\text { contemporáneo }\end{array}$ & \multirow[t]{2}{*}{ Artigo } & \multirow[t]{2}{*}{2014} & \multirow[t]{2}{*}{$\begin{array}{l}\text { Geografia e Ciências } \\
\text { Sociais }\end{array}$} \\
\hline & $\begin{array}{l}\text { Autores: Antonio Paolo Russo e Alan } \\
\text { Quaglieri Domínguez }\end{array}$ & & & \\
\hline \multirow[t]{2}{*}{4} & $\begin{array}{l}\text { Consumo colaborativo: tendência de } \\
\text { construção de conhecimento de negócios } \\
\text { no mercado digital de produtos usados }\end{array}$ & \multirow{2}{*}{ Artigo } & \multirow{2}{*}{2015} & \multirow{2}{*}{ Gestão e Conhecimento } \\
\hline & $\begin{array}{l}\text { Autores: Claudia Resem Paixão e Richard } \\
\text { Perassi Luiz de Souza }\end{array}$ & & & \\
\hline \multirow[t]{2}{*}{5} & $\begin{array}{l}\text { Proposição de uma escala para } \\
\text { mensuração do consumo colaborativo: } \\
\text { compreendendo o compartilhamento } \\
\text { de bens e a sua relação com os valores } \\
\text { pessoais }\end{array}$ & \multirow[t]{2}{*}{ Dissertação } & \multirow[t]{2}{*}{2015} & \multirow[t]{2}{*}{ Administração } \\
\hline & Autora: Helena Oliveira Dall Pizzol & & & \\
\hline 6 & $\begin{array}{l}\text { Las empresas de consumo colaborativo } \\
\text { Autora: Natalia Santolaria Carceller }\end{array}$ & $\begin{array}{l}\text { Trabalho de } \\
\text { conclusão } \\
\text { de curso }\end{array}$ & 2015 & $\begin{array}{l}\text { Comunicação Audiovisual } \\
\text { e Publicidade }\end{array}$ \\
\hline 7 & $\begin{array}{l}\text { Modelos de negócio na economia } \\
\text { compartilhada: uma investigação multi-caso } \\
\text { Autora: Ana Luisa Ilha Villanova }\end{array}$ & Dissertação & 2015 & Gestão Empresarial \\
\hline
\end{tabular}

Entre os trabalhos analisados, podemos catalogar um deles como “destoante" do conjunto de pesquisas encontradas. O artigo está categorizado como pertencente à área de Geografia, atrelada às Ciências Sociais. Nele, o "consumo colaborativo", como o proposto pelo Airbnb", é associado a um "novo conceito" de hospitalidade dentro de uma lógica espacial distinta do turismo tradicional.

A área de nosso maior interesse - comunicação e consumo - aparece apenas em um TCC, ${ }^{10}$ o que reforça a necessidade de os pesquisadores da área estarem atentos aos processos comunicacionais e à linguagem envolvida no "consumo colaborativo".

Em três trabalhos utilizou-se o termo "consumo colaborativo" como sinônimo de "economia compartilhada" e de "prática de compartilhamento”. No primeiro não há a preocupação em conceituar os termos empregados. Parte-se do pressuposto de que o leitor os conhece. Apenas no trabalho "Modelos de negócio na economia compartilhada:

9. O Airbnb é uma plataforma on-line que viabiliza o aluguel de imóveis ou parte deles entre interessados do mundo inteiro. Disponível em: <https://www.airbnb.com.br/>.

10. Muito embora tenhamos conhecimento de que outros trabalhos (também de conclusão de curso - inclusive na Universidade Federal de Pernambuco) foram defendidos com a temática. 
uma investigação multicaso", a autora explicita a compreensão de "consumo colaborativo" e "economia compartilhada" como sinônimos.

Mais do que um rigor epistemológico, tais constatações apresentam o conceito de "consumo colaborativo" como uma expressão ainda pouco questionada e, de antemão, referendada a partir do senso comum. Tal postura dos pesquisadores contribui para a supressão dos esclarecimentos acerca do conceito, mesmo se tratando de um trabalho que, explicitamente, se propõe a estudar o tema.

Além dessas primeiras evidências apontadas, nossa intenção ao fazer a busca nos repositórios era entender como a expressão "consumo colaborativo" está sendo utilizada na produção acadêmica. O que os pesquisadores entendem por "consumo colaborativo"? Como o definem? Para isso, analisamos cada trabalho como um todo, observando a sua área de origem e o seu respectivo lugar de fala, a abordagem geral, os propósitos do estudo, os subtemas tratados e as referências teóricas.

Por conseguinte, para maior compreensão a respeito da definição do termo, fizemos recortes nos trechos dos trabalhos que comportassem um esforço de conceituação do “consumo colaborativo”. Tal escolha foi feita porque entendemos que esses recortes - e não aqueles que expressam as condições, as caracterizações, as funções e os benefícios do que se convencionou chamar de "consumo colaborativo" - podem nos revelar mais diretamente se há (ou não) sintonia e homogeneidade em relação ao seu significado e de que modo isso ocorre.

Dois aspectos são ressaltados quando olhamos as definições de "consumo colaborativo" apresentadas nos trabalhos: a associação do conceito às práticas sustentáveis e a um maior nível de conscientização ou senso de responsabilidade por parte dos envolvidos na prática assim nomeada. Outro componente significativo está na emergência do compartilhamento e da troca - em vez da posse de bens. Vejamos a seguir cada um dos pontos aqui elencados mais detalhadamente.

\section{Consumo consciente, responsável e sustentável}

Não nos parece leviano afirmar que o principal alicerce estruturador dos trabalhos do nosso corpus é o entendimento de que o "consumo colaborativo" está diretamente relacionado à preocupação moderna com o bem comum e com o meio ambiente. Vários trechos ressaltam este aspecto: "No século XXI surge o consumo colaborativo, que é um movimento, criado nos Estados Unidos, que visa o consumo consciente e a melhoria da qualidade de vida para as gerações atuais e futuras" (ORNELLAS, 2012, p. 4, grifos nossos). Outro trabalho apresenta: "Se trata de viajeros expertos y conectados, proclives al consumo responsable" (RUSSO; DOMÍNGUEZ, 2014, s.p., grifo nosso).

Pois, entre outras ocorrências, há o processo de Consumo Colaborativo, que atua positivamente na geração de emprego e renda, revolucionando também as ações de consumo. [...] Isso amplia o tempo de vida útil e a função social dos produtos e caracteriza um conjunto de ações positivas, com relação à responsabilidade socioambiental. (PAIXÃO; SOUSA, 2015, p. 172, grifos nossos)

O novo modelo, ou padrão de consumo colaborativo, é baseado na colaboração em massa, na valorização da sustentabilidade, da 
redução do hiperconsumo, do desperdício e da reutilização dos produtos. (PIZZOL, 2015, p. 18, grifos nossos)

Apunta a las nuevas tecnologías como factor clave para el desarrollo de lo que ella ve como un modelo socioeconómico en auge porque es a través de estas que comunidades y ciudades "hacen más con menos": intercambian, alquilan, regalan, comparten y donan cosas a todas las escalas posibles, de la local a la mundial, pues internet no conoce límites. (CARCELLER, 2015, p. 4, grifos nossos)

Conforme exposto nos fragmentos aqui transcritos, a melhoria da qualidade de vida, sustentabilidade, consumo responsável, preocupação ambiental e social, redução de gastos e redução do próprio consumo são ideias ou termos constituintes do conceito de "consumo colaborativo" nos trabalhos do nosso corpus.

Tal compreensão fica evidente tanto quando são referendados outros autores para conceituar a expressão como também quando a construção do significado ocorre pelo próprio pesquisador. No entanto, nesse quesito, temos que demarcar a força da obra de Botsman e Rogers ${ }^{11}$ (2011), nos estudos avaliados. Presentes em todos os materiais analisados, os autores são apresentados como autoridades no tema.

Também recorrente é a preocupação em contextualizar os prejuízos causados pelo consumo na contemporaneidade. 0 crescimento das cidades, o aumento do trânsito e da poluição, o excesso do consumo, a descartabilidade dos bens, a finitude dos recursos, são temas quase sempre presentes e antecedentes à apresentação do "consumo colaborativo".

Parece-nos, portanto, que, no entender dos autores, o processo de mudança do consumo tradicional para o "consumo colaborativo" marcaria a transição de uma prática "vergonhosa” para outra "virtuosa". Assim, o "consumerismo"12 ocuparia o lugar do "consumismo"13, ou o "hiperconsumo"14 seria substituído pelo "autocontrole”, por "negócios mais justos” e "democráticos” e por relações que "não são obcecadas pelo material" - todos estes termos utilizados nos trabalhos analisados.

Um dos artigos afirma: "Assim, o desenvolvimento das atividades de consumo colaborativo, apesar de participar da atual cultura de mercado, se expressa como uma das tendências que equilibram ou ainda contrariam o consumismo" (PAIXÃO; SOUSA, 2015, p. 173).

Apesar da patente evidência da compreensão do "consumo colaborativo" como um fenômeno mais sustentável e crítico, há nos trabalhos a explicitação de uma prática de consumo sem julgamento de valor, conforme é possível perceber em alguns recortes: “[...] Consumo

11. Além da sua presença nos sete trabalhos, a obra exerce muita força na construção dos argumentos por parte dos pesquisadores e pode ser entendida como a maior referência no assunto do consumo colaborativo.

12. Conceito adotado para se opor ao termo consumismo. É entendido como um consumo que proporciona o equilíbrio entre produtores, distribuidores e consumidores.

13. Dá ideia de excesso de consumo.

14. De acordo com Lipovetsky (2007, p. 24), o hiperconsumo existe na perspectiva de uma felicidade, nomeada pelo autor de "paradoxal". A sociedade atual pensaria, produziria e organizaria tudo, com vista à nossa maior felicidade e à medida que a produção gerasse consumo e riquezas, este mesmo consumo elevaria as nossas necessidades de consumir e promoveria a mercantilização das necessidades. 
Colaborativo, em que pessoas estão compartilhando produtos e serviços com suas comunidades através de escritórios, vizinhanças, condomínios, escola ou via Facebook.” (ORNELAS, 2012, p. 51, grifo nosso).

Porém, o Consumo Colaborativo não se restringe às ações decorrentes da conscientização sobre a responsabilidade socioambiental, porque esse é primeiramente caracterizado pelo compartilhamento de informações, conhecimentos e produtos em processos que podem ser motivados por diversos interesses distintos. (PAIXÃO; SOUSA, 2015, p. 176, grifo nosso)

A delimitação do conceito de consumo colaborativo, de acordo com Belk $(2007,2013)$ passa pela necessidade de considerar a aquisição $e$ distribuição dos recursos durante as atividades entre os indivíduos. A partir dessa premissa, o consumo colaborativo ocorre nos eventos coordenados entre os consumidores para a aquisição e distribuição de um recurso a partir de um valor ou outra forma de remuneração, como, por exemplo, escambo, comércio e trocas que envolvam a compensação não-monetária. (PIZZOL, 2015, p. 27, grifos nossos)

Como visto, é notório que existe, por parte dos autores, uma consciência das questões mais práticas e operacionais que estão inseridas no processo do que classificam como sendo o "consumo colaborativo". No entanto, apesar dessas ponderações estarem presentes nos textos, uma análise geral nos permite compreender que eles parecem ter menor relevância ou destaque diante da exposição dos aspectos positivos, como mencionamos anteriormente.

Uma das razões para a associação entre "consumo colaborativo" e consumo responsável pode estar relacionada à potencialização do compartilhamento e da troca de bens em detrimento da posse, questão esta que será mais debatida no próximo tópico.

\section{O compartilhamento e a troca como substitutos da posse}

Também presente em quase todos os trabalhos analisados está a questão da posse do bem como algo que é atualizado e, consequentemente, revisto e substituído no "consumo colaborativo". Entram em cena o compartilhamento e a troca como elementos quase inerentes à prática de consumo aqui analisada. Muito embora seja mister destacar: não é recente, nem exclusivo do tipo de consumo que estamos tratando - o compartilhamento como forma de consumir.

Vejamos alguns trechos que tratam dessa abordagem:

O Consumo Colaborativo é colocar um sistema em um lugar onde pessoas podem compartilhar recursos sem sofrerem penalidades por isso, com liberdade ou sacrifício as suas vidas. $O$ conceito de não ser dono ou não ter posse não é recente. (ORNELLAS, 2012, p. 52, grifos nossos)

Nesse sentido, o ato de consumir deixa de ser representado exclusivamente pela compra e posse de bens e abre espaço para novas possibilidades, como as iniciativas colaborativas, representadas por ações de trocas, empréstimos, aluguéis e outras formas de compartilhamento que permitem aos consumidores o acesso a um bem ou serviço apenas no tempo que julgam necessário. (PIZZOL, 2015, p. 15, grifo nosso)

Rachel Botsman, una de las inspiradoras del movimiento de la economía colaborativa, a través de su libro What's Mine is Yours, explica 
en su blog que se trata de un nuevo modelo económico que "describe un cambio en los valores del consumidor: de la posesión al acceso". [...] Cañigueral lo explica con palabras más didácticas en la página 25 de su libro Vivir mejor com menos, pero que coinciden con los conceptos de Botsman: es un nuevo modelo económico que propone "compartir bienes frente a poseerlos, y focalizarse en poner en circulación todo aquello ya existente. Pasar de entender el consumo como propiedad a entender el consumo como acceso y uso". (CARCELLER, 2015, p. 4, grifos nossos)

Para Gansky (2010), economia compartilhada, ou mesh, é um sistema socioeconômico construído em torno do compartilhamento de recursos humanos e físicos, o qual inclui a criação, produção, distribuição, comércio e consumo compartilhado de bens e serviços por pessoas e organizações. Botsman e Rogers (2011) conceituam a economia compartilhada, ou consumo colaborativo, como um conjunto de práticas comerciais que possibilitam o acesso a bens e serviços, sem que haja, necessariamente, a aquisição de um produto ou troca monetária entre as partes envolvidas. Estas práticas são constituídas por transações como o compartilhamento, empréstimo, aluguel, doação, trocas, e escambo. (VILLANOVA, 2015, p. 8, grifos nossos)

A ideia do compartilhamento além de se mostrar como uma nova forma de consumir acaba por reforçar a compreensão do termo como algo “melhor”. Isto é, como um processo que afetará menos o mundo já que a produção de bens será minimizada e o ciclo de vida do produto ampliado.

Interessante observar também que, na maioria das vezes, a explanação sobre o compartilhamento em detrimento à posse no “consumo colaborativo" está relacionada a um cenário sem prejuízos para o consumidor. Isso significa que os trabalhos pesquisados retratam uma dinâmica que possibilitará ao indivíduo consumir quando for necessário e viver melhor com menos, sem que ele tenha desvantagens.

Tal posicionamento dos pesquisadores diante do conceito - tanto no que diz respeito ao "consumo colaborativo" como algo sustentável como no que se refere à ausência da posse do bem - corrobora a necessidade investigarmos as publicações em busca da construção de um conceito bem fundamentado.

\section{CONSIDERAÇÕES FINAIS}

Agrupar e analisar trabalhos publicados sobre determinado tema não é suficiente para compreendê-lo como um todo. É evidente que também enriquece o conhecimento sobre algo olhar para o objeto de estudo e ter liberdade para fazer outras associações teóricas, independentes daquelas que são postuladas nos trabalhos já existentes. No entanto, fazer um recorte de como os pesquisadores tratam o "consumo colaborativo" nos permite iniciar algumas inferências a respeito do conceito que buscamos - o que pode ser muito interessante, especialmente porque temos o desafio de estruturar, nos próximos anos, uma tese de doutorado com tal perspectiva.

Nesse propósito de reunir as publicações do Portal de Periódicos da Capes/MEC e da BDTD, alguns aspectos nos chamaram atenção. Merecem destaque três deles: 1 ) a referência "base", retratada na utilização e concordância dos pesquisadores com a obra $O$ que é meu é seu: como o consumo colaborativo vai mudar o nosso mundo (2011), presente em todos os trabalhos; 2) a relação de posse e compartilhamento com os bens 
consumidos; 3) o tratamento do "consumo colaborativo" como uma prática sustentável, que visa minimizar os prejuízos do consumo excessivo.

A obra mencionada, como contextualizamos anteriormente, firmase diante dos trabalhos sucessores analisados, como o estudo de maior força a respeito do tema. Seus preceitos são reproduzidos quase sem questionamentos nos artigos e dissertações estudadas. Para além do fato de a perspectiva adotada por Botsman e Rogers (2011) não ser a ideal, pelo menos a nosso ver, a fidelização à obra vem proporcionando um entendimento uníssono sobre o "consumo colaborativo", quase "discipular".

A respeito do segundo aspecto, é interessante refletir que a história do consumo nos remete à posse. Consideraríamos como "consumo" o ato a partir do qual um objeto se tornasse nosso ou por nós fosse consumido. No entanto, essa construção parece sofrer uma ruptura a partir do "consumo colaborativo" ${ }^{15}$. As mídias sociais digitais, privilegiam o acesso. Não é mais necessário ter algo, porque isso implica em custos, espaço físico e acúmulo de bens. Já o acesso via compartilhamento fazem referência a processos mais práticos, comuns e com boa conotação.

Sobre a crença do consumo colaborativo como um processo que beneficia a sociedade e o meio ambiente, nos perguntamos: será que o consumo em rede reforçou ou potencializou a sensibilidade das pessoas em relação ao bem comum e a sustentabilidade? Por que o consumo colaborativo é tão relacionado a esses aspectos mais humanísticos e ambientais?

Provavelmente as ferramentas tecnológicas não tenham alterado a percepção das pessoas em relação a esses temas, ou se o alterou, não ocorre de modo tão determinante como a princípio parece postular o pensamento genérico "agora que podem consumir colaborativamente, os indivíduos e empresas praticam o bem”.

Não entendemos que a comunicação em rede e o melhor acesso à internet proporcionaram um consumo mais ético. Acreditamos que as temáticas do "bem comum" são presentes nos exemplos de "consumo colaborativo” porque elas veem sendo discutidas há bastante tempo em outros âmbitos sociais. Soma-se a isso o fato de que as responsabilidades ambiental e social já foram impostas às empresas. Os consumidores, por sua vez, igualmente refletem sobre o processo de produção e distribuição daquilo que desejam consumir.

É evidente que nem todas as organizações e nem todos os indivíduos se preocupam com esses aspectos e agem assim. Mas imaginamos que a maior evidência nas práticas de consumo voltadas a minimizar a utilização de recursos naturais e o bem da sociedade estão mais relacionadas à facilidade de reunir pessoas com o mesmo interesse ou objetivo do que a um processo diretamente oriundo das condições do nomeado "consumo colaborativo".

Assim, cremos que o "consumo colaborativo" que aflora com o favorecimento das redes sociais digitais, a princípio, não é sinônimo de uma maior consciência crítica do consumidor e das instâncias produtivas. Tampouco é uma condição para que determinada ação seja considerada como um tipo de consumo de essência colaborativa. Por outro lado, a maior circulação de informações e a maior facilidade para concretizar

15. Esta afirmação não significa que não havia práticas de empréstimos, doações e uso compartilhado anteriormente. Do mesmo modo que o consumo colaborativo sempre existiu - mesmo de modo diferente -, outras relações com o bem além da posse também sempre foram presentes em sociedades anteriores. 
ações coletivas podem ter permitido a divulgação e a concretização de formas de consumo que antes eram tanto desconhecidas quanto inacessíveis para muitos. Dito de outra forma, não há como negar as potencialidades da comunicação digital em rede para fazer com que mais pessoas consumam produtos e serviços a partir da troca e/ou do compartilhamento e com melhorias para o ambiente.

Ademais, a relação que os pesquisadores de "consumo colaborativo" (aqui, minimamente representados pelo nosso recorte metodológico) fazem da sustentabilidade e do bem comum talvez esteja vinculada às pesquisas empíricas realizadas. Nestas, ao demonstrar as motivações e benefícios percebidos pelos entrevistados, fica explícito o interesse destes em contribuir para o bem-estar de pessoas e do mundo. Mas é importante destacar que estes não são os únicos aspectos que influenciam a participação em uma prática de "consumo colaborativo". A praticidade e o preço também surgem como justificativas da inclusão dos indivíduos no processo.

Além disso, não há como deixar de ressaltar que tais discursos podem ser resultantes de uma estratégia das empresas que propõem o consumo colaborativo. Elas propagam que a sua oferta pode beneficiar a sociedade e o indivíduo como forma de atrair seu público.

Com efeito, ao recuperarmos o nosso intento primordial - o de pensarmos em um conceito de "consumo colaborativo" que verdadeiramente "dê conta" do seu caráter multifacetado -, talvez a maior parte dos aspectos aqui elencados não deva ser considerada. A construção semântica de um campo que visa conferir, de forma relevante, significação para um conceito ainda nebuloso e amorfo deve abordar, a nosso ver, entre outras coisas, as características gerais da prática, e não as motivações extrínsecas e intrínsecas, bem como os seus benefícios percebidos. Caso contrário, estaríamos delimitando uma prática à intenção subjetiva de um sujeito, sem nem ao certo sabemos se realmente é aquilo que o norteia quando pratica o "consumo colaborativo", ou se é apenas uma estratégia discursiva para se isentar da eventual "culpa do consumo". Assim, defendemos que o "consumo colaborativo" deve estar relacionado ao modo de consumir, e não à motivação que o engendra.

É preciso dizer, igualmente, que o entendimento mais "objetivo" (se assim podemos definir) sobre o "consumo colaborativo" também está presente nos trabalhos analisados, porém com menor ênfase. Demonstramos anteriormente trechos em que há menção ao "consumo colaborativo" como parte da ação em que uma ou mais pessoas consomem bens e serviços colaborativamente.

Tais questões apresentadas ao longo deste artigo apenas reforçam a necessidade de um maior tensionamento sobre a naturalização do conceito de "consumo colaborativo". Também vemos como fundamental não perder de vista os processos sociais, políticos e econômicos que proporcionam o cenário atual e que interferem em sua formação. Com isso, queremos dizer que o tom mais afetuoso a respeito do termo pode estar obscurecendo aspectos não tão aparentes no senso comum: a compreensão do "consumo colaborativo" como um processo resultante e inserido no capitalismo.

Assim, instiga-nos continuar a refletir se a forma como o consumo colaborativo é compreendido e tratado não está relacionado a um interesse de neutralizar os problemas mais típicos do capitalismo ou até mesmo de atribuir ao indivíduo a possibilidade ou responsabilidade de dissipar o "mal do mundo". Isso porque, a partir do momento em que 
enxergamos em qualquer pessoa a solução para os maiores problemas da sociedade - poluição, escassez de recursos naturais e falta de acesso aos bens - talvez estejamos legitimando a responsabilização dos sujeitos em detrimento dos maiores provocadores de tal cenário: grandes empresas e conglomerados.

Entendemos que essa pesquisa não se conclui com este trabalho. Continuar a observar o estado da arte da expressão nos desafia a buscar uma conceituação mais problematizada e consolidada. Mais do que isso, nos permitirá entender as alterações nas lógicas do consumo e investigar que processos e fatores contribuem e são relevantes na construção do cenário atual. A nosso ver, esforço de extrema relevância para a pesquisa no campo que entrelaça comunicação e consumo.

\section{REFERÊNCIAS}

ALGAR, R. Collaborative Consumption. Oxygen Consulting, Bringhton, 2007. Disponível em: <https://goo.gl/W4e4sQ>. Acesso em: 17 jul. 2016.

BELK, R. You are what you can access: sharing and collaborative consumption online. Journal of Business Research, Amsterdam, v. 67, n. 8, p. 1595-1600, 2013.

BOTSMAN, R.; ROGERS, R. O que é meu é seu: como o consumo colaborativo vai mudar o nosso mundo. São Paulo: Bookman, 2011.

CARCELLER, N. S. Les empreses de Consum Col-laboratiu. 2015. 94 f. Treball de Projecte, Bachelor Thesis (Comunicació Audiovisual i de Publicitat) - Universitat Autònoma de Barcelona, Barcelona, 2015.

FELSON, M.; SPAETH, J. L. Community structure and collaborative consumption: a routine activity approach. American Behavioral Scientist, Thousand Oaks, v. 21, n. 4, 1978.

LIPOVETSKY, G. A felicidade paradoxal: ensaios sobre a sociedade de hiperconsumo. Trad. de Maria Lúcia Machado. São Paulo: Companhia das Letras, 2007.

ORNELLAS, R. S. O consumo colaborativo de transporte individual car sharing e o processo decisório do consumidor do consumidor na cidade de São Paulo. 2012. 151 f. Dissertação (Mestrado em Administração) - Faculdade de Economia, Administração e Contabilidade, Universidade de São Paulo, São Paulo, 2012.

- Impactos do consumo colaborativo de veículos elétricos na cidade de São Paulo. Future Studies Research Journal, São Paulo, v. 5, n. 1, p. 33-62, jan./jun. 2013.

PAIXÃO, C. R.; SOUSA, R. P. L. Consumo colaborativo: tendência de construção de conhecimento e negócios no mercado digital de produtos usados. Perspectivas em Gestão \& Conhecimento, João Pessoa, v. 5, n. 2, p. 170-185, jul./dez. 2015.

PIZZOL, H. O. D. Proposição de uma escala para mensuração do consumo colaborativo: compreendendo o compartilhamento de bens e a sua relação com os valores pessoais. 2015. 166 f. Dissertação (Mestrado em Administração e Negócios) - Faculdade de Administração, Contabilidade e Economia, Pontifícia Universidade Católica do Rio Grande Do Sul, Porto Alegre, 2015

RUSSO, A. P.; DOMÍNGUEZ, A. Q. La lógica espacial del intercambio de casas: una aproximación a las nuevas geografías de lo cotidiano en el turismo contemporáneo. Scripta Nova: Revista Electrónica de Geografía y Ciencias Sociales, Barcelona, v. XVIII, n. 483, s/p, jul. 2014

VILLANOVA, A. L. I. Modelo de negócio na economia compartilhada: uma investigação multicaso. 2015. 125 f. Dissertação (Mestrado em Gestão Empresarial) - Escola Brasileira de Administração Pública e de Empresas, Centro de Formação e Pesquisa, Fundação Getúlio Vargas, Rio de Janeiro, 2015. 